\title{
Relato de Experiência: a construção da mão biônica como modelo didático no ensino de Ciências
}

\author{
Experience report: the building of the bionic hand as a teaching model in the \\ Science class
}

\author{
Guilherme Pinheiro Furusawa ${ }^{1}$ \\ Nathália Calegari Forcato ${ }^{2}$
}

\begin{abstract}
RESUMO
A instrumentação do ensino com o uso de modelos didáticos, construídos pelos alunos, se mostra uma ferramenta eficaz, lúdica, capaz de auxiliar na observação e na concretização de diversos conteúdos curriculares do ensino de Ciências. Dentro da temática do Corpo Humano, para que os alunos compreendam a relação entre os músculos e os movimentos do corpo, faz-se fundamental que conheçam o papel dos tendões, estrutura que tem a função de conectar as peças anteriores. Dessa forma, os alunos do $8^{\circ}$ ano do Ensino Fundamental construíram uma mão biônica, com objetivo de simular o funcionamento do movimento do antebraço e mão humana. Valendo-se de sucata, onde o papelão, reutilizado de caixas, deu a forma anatômica de um dos membros anteriores humano, e cordões simularam os tendões do antebraço e mão, proporcionando a compreensão destas importantes estruturas biológicas. Ainda trabalharam, de forma interdisciplinar, com conteúdos de Literatura e Educação Física na compreensão da relação existente entre as Ciências Naturais e a qualidade de vida. O trabalho em tela objetivou relatar um exemplo bem-sucedido de aula prática, apoiado em modelo didático, de baixo custo e interdisciplinar.
\end{abstract}

Palavras chave: modelos didáticos no ensino de Ciências, Ensino Fundamental, corpo humano, Mão Biônica.

\begin{abstract}
The use of teaching tools with didactic models, built by the students, proves to be an effective, playful practice, capable of assisting in the observation and implementation of various curricular contents in the teaching of Sciences. Within the theme Human Body, for students to understand the relationship between muscles and body movements, it is essential that they know the role of tendons, a structure that has the function of connecting the previous pieces. For this reason, students in the 8th year of elementary school built a bionic hand, with the objective of simulating the functioning of the forearm and human hand. Using scrap, where cardboard, reused from boxes, gave the anatomical shape of one of the human forelimbs, and cords simulated the tendons of the forearm and hand, providing an understanding of these important biological structures. They also worked, in an interdisciplinary way, with contents of Literature and Physical Education in understanding the relationship between the Natural Sciences and the quality of life. The work on screen aimed to report a successful example of practical class, supported by a didactic, low-cost and interdisciplinary model.
\end{abstract}

Keywords: didactic models in Science teaching, Elementary School, human body, bionic hand.

\footnotetext{
${ }^{1}$ Prof. Doc. I (Biologia) Colégio Estadual Dr. João Nery/ SEEDUC-RJ; doutorando no PPGCV/UFRRJ. gfurusawa@gmail.com.

${ }^{2}$ Prof. Doc. I (Ciências) Colégio Estadual Dr. João Nery / SEEDUC-RJ. nathcforcato@ gmail.com.
} 


\section{Introdução}

Os recursos digitais, modelos didáticos, capacitação de professores, entre outros, embora já existam, ainda não lograram atender todos os anseios nas diversas escolas públicas de ensino básico fluminense. Assim, as equipes escolares buscam desenvolver e valorizar estratégias que consigam atender estas necessidades. Sobretudo em disciplinas que apresentam a virtualidade em boa parte de seus conteúdos, como acontece nas Ciências da natureza e na Matemática, que necessitam de instrumentos e recursos didáticos que promovam minimizar essa problemática da tangibilidade.

Assim, estas estratégias têm tornado as aulas mais interessantes, além de proporcionar a observação e o debate sob diversas lentes.

As Orientações Curriculares para o ensino de Ciências no $8^{\circ}$ ano do Ensino Fundamental apresentam, em um de seus objetivos, reconhecer a importância da integração dos sistemas do corpo humano sob ação de diferentes estímulos: coordenação e equilíbrio. Tendo como conteúdo: Sistema locomotor, ossos e músculos e, como habilidade: identificar o conjunto ósseo muscular como arcabouço estrutural e de movimento do corpo humano (RIO DE JANEIRO, 2010). Entretanto, para que haja conexão entre esses órgãos, existe uma importante estrutura, normalmente ignorada: os tendões, cuja função, nessa abordagem, é a conexão entre os ossos e os músculos. Para que os alunos conseguissem tocar e construir esse conhecimento, utilizou-se de um instrumento para que essa conexão fosse simulada. Essas aulas alicerçaram-se na construção, pelos alunos, de uma Mão Biônica de papelão, como modelo didático e instrumento de ensino, proporcionando aos alunos diferentes descobertas tendo como ponto de partida, a construção deste artefato.

\section{Norteamento teórico}

Acerca das chamadas aulas práticas, Torquemada-Guerra (2010) observa que nas mudanças curriculares ocorridas pela publicação da LDB em 1961, conjeturaram uma nova forma de se entender o ensino e a escola. Dessa forma, o objetivo fundamental do ensino de Ciências passou a ser o de dar condições para o aluno identificar problemas a partir da investigação e observação sobre um determinado fato, levantar hipóteses, testá-las, refutá-las e abandoná-las quando fosse o caso, trabalhando de forma a tirar conclusões sozinho, construir o conhecimento e assim houve, a inclusão das chamadas $a u$ las práticas, baseadas em experimentações. $\mathrm{O}$ aluno deveria ser capaz de redescobrir o já conhecido pela ciência, apropriando-se da sua forma de trabalho, compreendida então com o método científico: uma sequência rígida de etapas preestabelecidas. É com essa perspectiva que se buscava, desde aquela ocasião, a democratização do conhecimento científico, reconhecendo-se a importância da vivência científica não apenas para eventuais futuros cientistas, mas também para o cidadão comum.

Ainda nesse contexto, os PCNs para as Ciências Naturais (BRASIL, 
1998) argumentam que os procedimentos fundamentais para possibilitar a aprendizagem em Ciências Naturais são aqueles que permitam a construção do conhecimento através da investigação, da comunicação e do debate de fatos e ideias como também, da observação, da experimentação, da comparação, do estabelecimento de relações entre fatos ou fenômenos e ideias, da leitura e da escrita de textos informativos, da organização de informações por meio de desenhos, tabelas, gráficos, esquemas e textos, da proposição de suposições, do confronto entre suposições e entre elas e dos dados obtidos por investigação, da proposição e a solução de problemas. Da mesma forma, a BNCC dá atenção especial a esse letramento científico. Considerando que, mais do que conhecer conceitos, os alunos precisam ser habilitados a compreender e a interpretá-los, bem como transformá-los e utilizá-los para um bem maior, ou seja, interferir nele de forma consciente, sabendo que suas ações têm consequências que podem ser refletidas na vida individual e coletiva.

Baseado nisso, quando um aluno é desafiado a montar um instrumento que lhe proporcione visualizar, deduzir, descobrir temas complexos, de certa maneira, consolida a ideia da construção do conhecimento, criando perguntas e possibilidades, bases desse letramento científico. Nesse sentido, Souza (2007, p. 111) definiu os instrumentos de ensino como sendo todo material utilizado como auxílio no ensino e aprendizagem do conteúdo proposto para ser aplicado, pelo professor, a seus alunos, afirmando ainda que precisam ser variados e diversificados, para dinamizar o ensino de conteúdos, muitas vezes abstratos, principalmente no ensino de ciências e biologia.

Da mesma forma, Bonzanini (2016) afirma que os instrumentos de ensino, quando bem selecionados e utilizados, contribuem para um ensino mais atual e dinâmico, favorecendo a construção e compreensões de novos conceitos. A utilização de modelos didáticos situa-se neste contexto.

Seguindo na direção da edificação do conhecimento e letramento científico, a interdisciplinaridade apresentase como uma ferramenta fundamental. Segundo Fazenda (2002), essa ferramenta baseia-se no conhecimento de várias disciplinas para resolver um problema concreto, compreendendo um determinado fenômeno sob diferentes pontos de vista, e, neste cenário, ela é proposta de modo a contribuir para superar a dissociação do conhecimento produzido, visando orientar o erguimento de uma nova ordem de conhecimento, criando novos horizontes, novas analogias, nova linguagem e novas estruturas conceituais. Estabelecendo o diálogo entre disciplinas, eliminando as barreiras artificialmente postas entre as ciências, tornando-se um instrumento importante na construção do conhecimento.

Essa visão e proposta de trabalho auxiliam na criação de hábitos intelectuais que obrigam a levar em consideração as intervenções humanas em algumas das diversas perspectivas e pontos de vista possíveis.

A interdisciplinaridade como ferramenta eficiente deve partir de prin- 
cípios simples e até temáticos da vivência cotidiana, caminhando paralela aos anseios e necessidades da transformação social de forma consciente e direcionada, respeitando e aproveitando o saber acumulado. Esta modalidade de organização do currículo, na medida em que desperta o interesse e a curiosidade dos estudantes, através de questões reais, práticas e de interesse social, levaos a analisar os problemas, procurando soluções, incentivando então a formação de pessoas criativas e inovadoras (SANTOMÉ, 1998; FAZENDA, 2002).

Dessa forma, a construção desses modelos didáticos, logram a sociabilidade entre os alunos, trabalhando com estética, criatividade, cognição motora e, quando o modelo em questão relaciona-se com a morfologia humana, geram ainda conhecimento acerca da forma e funcionamento do próprio corpo, estimula o espelhamento e autoconhecimento.

De igual modo, a Educação Física, que até pouco tempo criam restringir-se apenas à prática desportiva, hoje relaciona-se com conceitos associados à qualidade de vida em seu sentido mais amplo. No currículo abordado pela disciplina, os alunos passeiam pelos conhecimentos sobre o corpo humano, convidados a trabalhar temas como: elementos de estrutura do corpo (anatomia); elementos de funcionamento interno do corpo (fisiologia); compreensão do processo de movimento do corpo (cinesiologia); entendimento sobre a construção cultural do corpo (antropologia); e as relações sociais que se estabelecem a partir desse corpo (soci- ologia). Além, naturalmente, da manutenção da saúde e a profilaxia de lesões associadas à prática desportiva. Integrando-se assim, aos debates assinalados pelo trabalho em questão (RONDINELLI, 2020, p.1).

O trabalho em tela objetivou apresentar um modelo de trabalho de baixo custo, através do aparelhamento por modelo didático, construído e trabalhado de forma interdisciplinar, que proporcionou aos alunos a compreensão, através deste instrumento, da função dos tendões nos movimentos esqueléticos do corpo humano, por meio da conexão entre nossos ossos e músculos. Além disso, compreenderam formas de se evitar tendinites, que são irritações ou inflamações nestas estruturas, a importância dos aquecimentos e alongamentos antes e/ou depois das práticas desportivas ou outros exercícios físicos inerentes ao cotidiano. Logrou ainda amostrar ao longo da História, situações em que o conhecimento acerca dos tendões esteve presente.

\section{Metodologia}

O trabalho foi desenvolvido em conjunto por professores de Ciências e Educação Física, equipe pedagógica desta unidade de ensino e com alunos do $8^{\circ}$ ano do Ensino Fundamental, turma 801, do Colégio Estadual Dr. João Nery, Mendes-RJ, durante as aulas dessas disciplinas, nos meses de agosto e setembro de 2019. Em um primeiro momento, os alunos distribuíram-se em pequenos grupos e receberam as orientações acerca da construção da Mão Biônica de papelão (Figuras 1 
e 2) cuja fabricação é ensinada em diversos canais no YouTube ${ }^{\circledR}$. Para a confecção do artefato, os alunos receberam papelões (de caixas reutilizadas), canudinhos descartáveis, cola quente e cordões de algodão (Figuras 3 a 11). Em seguida estimulou-se a percepção dos alunos para a relação existente entre seu mecanismo e os tendões de um braço humano (Figura 12). 
Figuras. 1 e 2: Modelo da Mão Biônica, construído como modelo, pelos professores de Ciências.
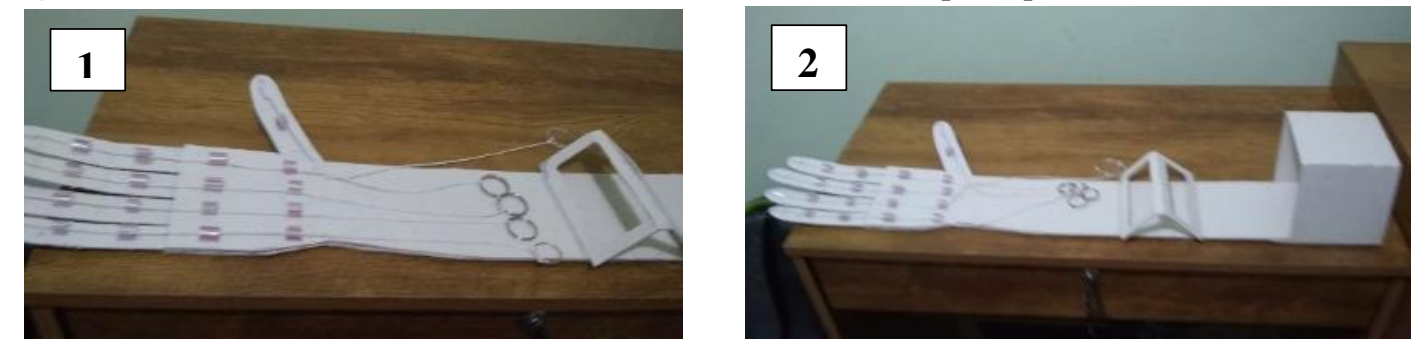

Fonte: acervo pessoal

Figuras. de 3 a 11- Alunos da turma 801 de 2019, confeccionando a Mão Biônica, com destaque ao uso de material reutilizado.
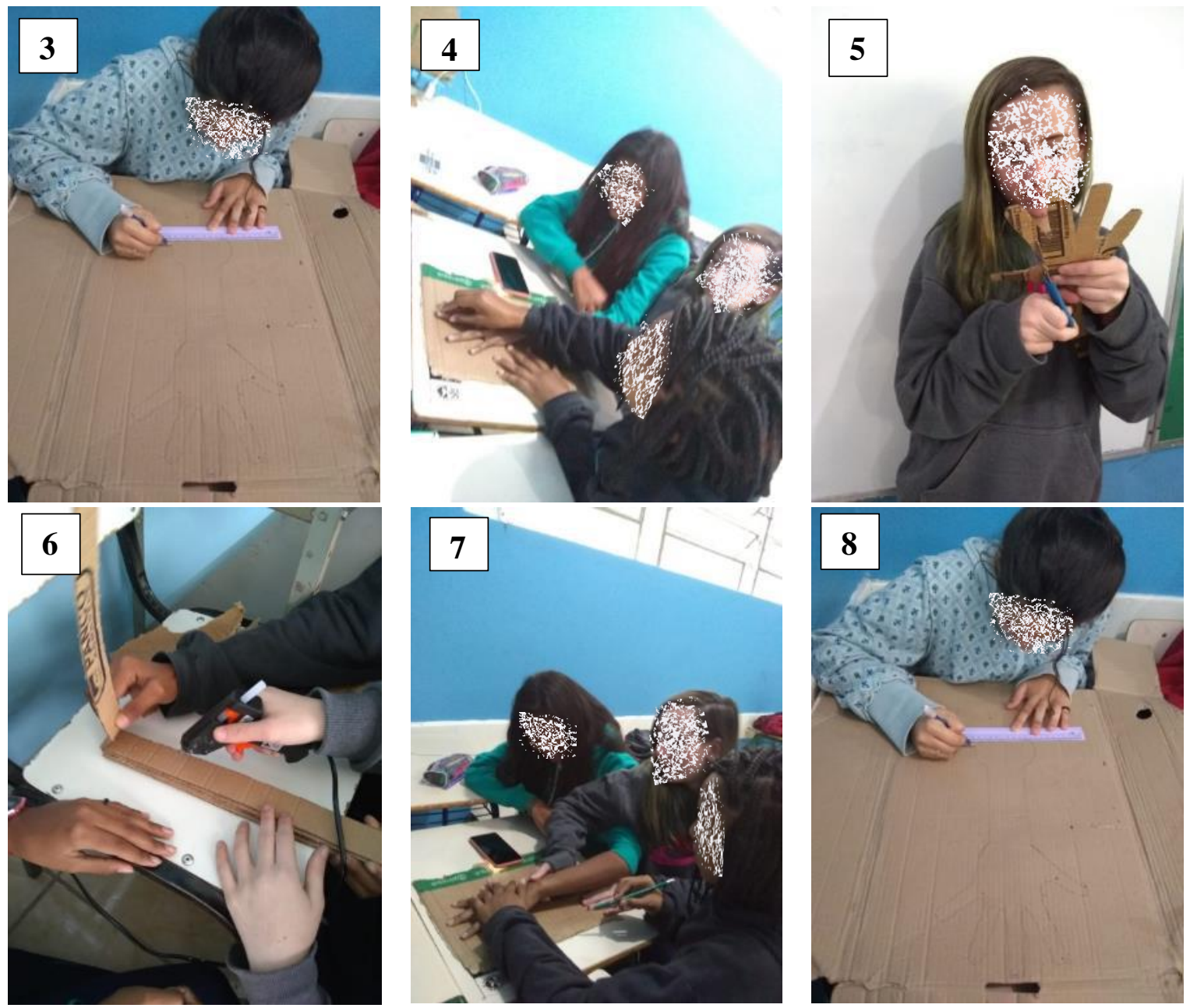

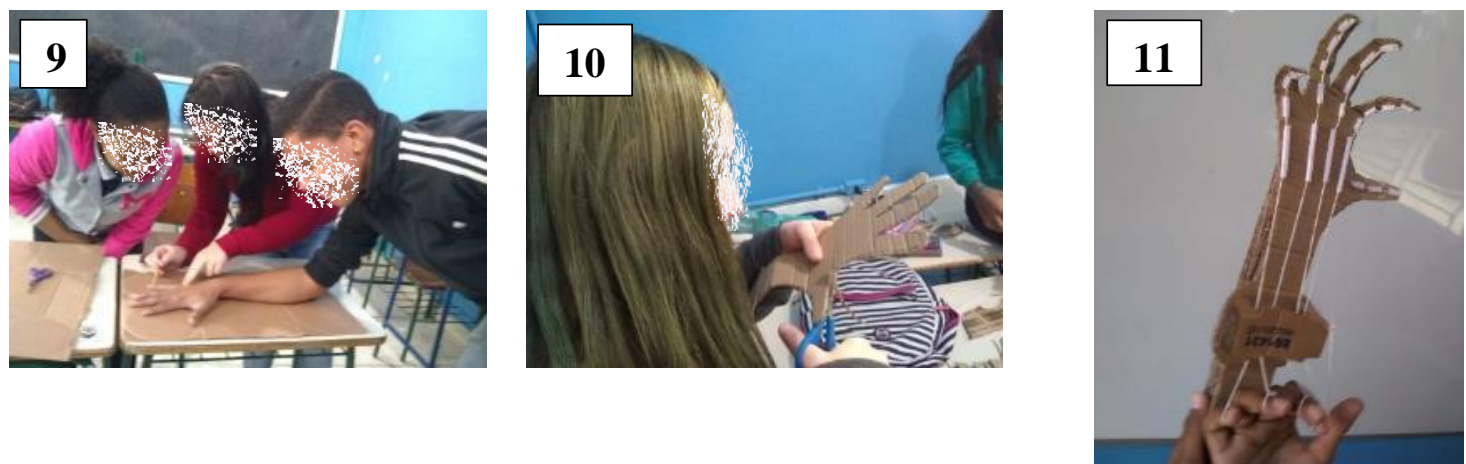

Fonte das imagens 3 a 11: acervo pessoal. As imagens foram alteradas para preservar a identidade dos participantes.

Figura 12- modelo de mão esquerda evidenciando seus tendões.

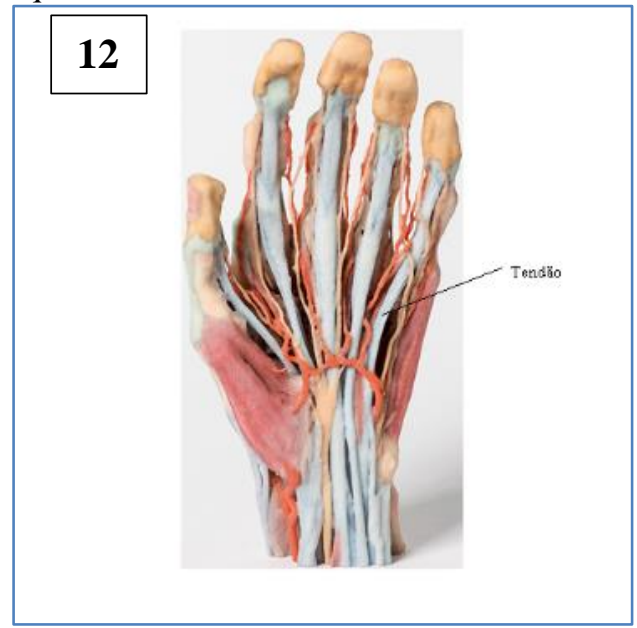

Fonte: http://erler-zimmer.com.br/modelos-anatomicos/modelo-de-mao-esquerda-com-disseccao-superficial-mp1530/ Acessado em 18 de set. 2019 [adaptado]).

No segundo momento os alunos puderam compreender a mecânica dos movimentos dos dedos e movimentos flexores e extensores do pulso, através do modelo da Mão Biônica, observando a ação dos músculos por meio dos tendões.

Em seguida os alunos discutiram, sob a orientação de um professor de Educação Física da unidade de ensino, acerca de problemas que normalmente envolvem os tendões, como as tendinites resultantes do esforço repetitivo, atletas que tiveram suas carreiras comprometidas nos esportes por problemas relacionados aos tendões e até a saga do herói grego Aquiles, que rompeu o tendão calcâneo, seu ponto vulnerável, além de formas de alongamento e aquecimentos que visam preservar os tendões, ligamentos e músculos (Figura 13). 
Fig. 13- Alunas da turma 801 do ano de 2019 demonstrando uma técnica de alongamento para prevenção de problemas relacionados aos músculos e tendões das mãos e antebraços. Técnica ensinada pelo docente de Educação Física desta Unidade de ensino.

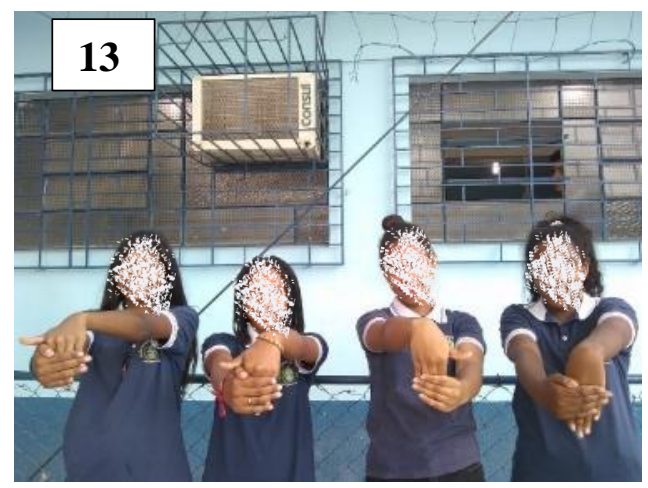

Fonte: acervo pessoal.

Por fim, o projeto foi submetido e selecionado para ser apresentado na IV FIMUCTI, feira intermunicipal de ciência, tecnologia e inovação do Vale do Café, realizada na cidade de Mendes-RJ, onde os alunos puderam desenvolver uma exposição sobre os tendões, suas funções e a profilaxia de doenças associadas aos mesmos e apresentarem os modelos didáticos desenvolvidos (Imagens 14 e 15). Todos os alunos da turma participaram do evento, entretanto, por norma da feira, apenas três alunos representaram a turma na exposição. Esses alunos se candidataram e foram eleitos pelos demais, valorizando o protagonismo e a iniciativa (Imagens 16 a 18). Vale ressaltar que, todos os pais e/ou responsáveis legais dos alunos manifestaram anuência na participação de seus tutelados neste projeto, assim como no uso de imagem, tanto na IV FIMUCTI quanto nesta publicação, assinando termo de consentimento livre e esclarecido. 
Imagens 14 e 15- Banners desenvolvidos pelos alunos da turma 801, resumindo todos os assuntos trabalhados no projeto, apresentados na IV FIMUCTI, Mendes-RJ. No banner 14 apresentaram o desenvolvimento do projeto. No banner 15 apresentaram a aplicação, os aspectos lúdicos e as curiosidades descobertas durante o desenvolvimento do projeto.
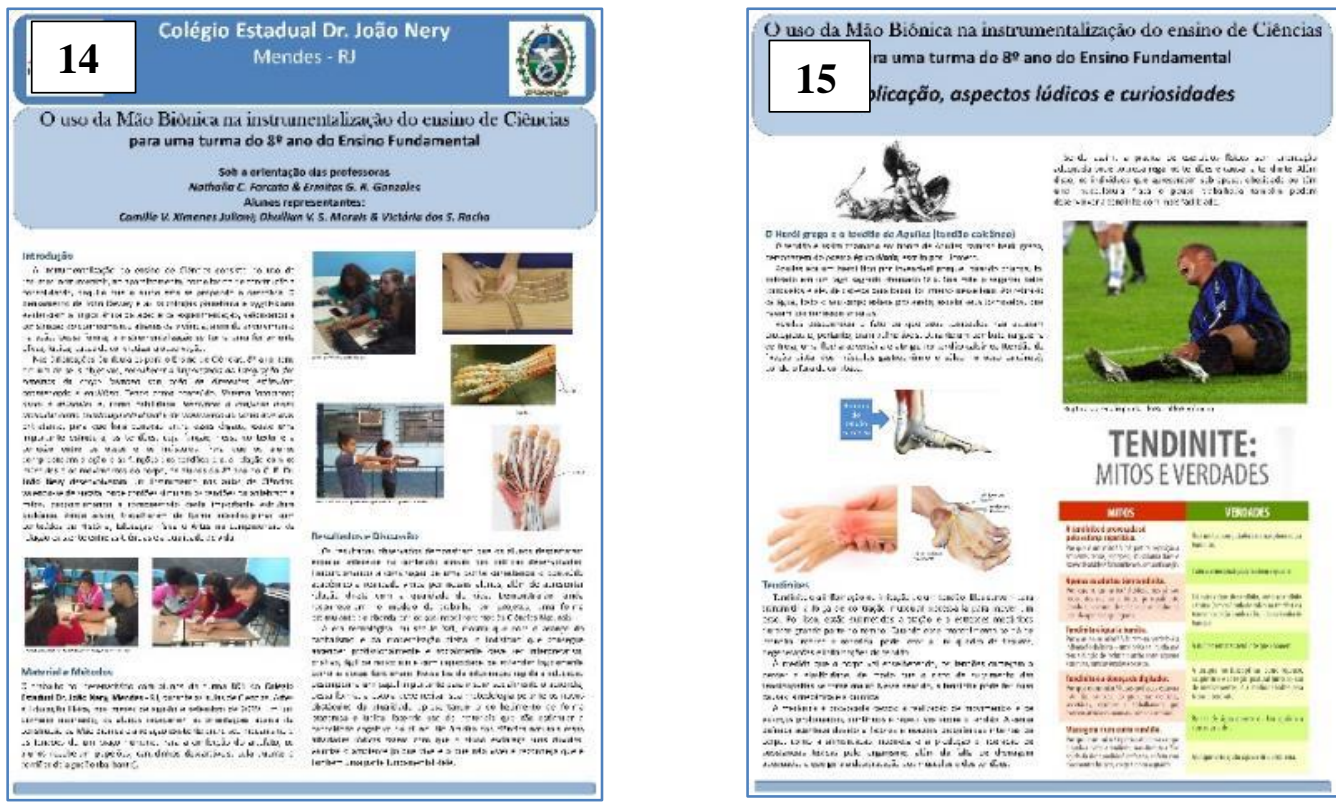

Figuras. 16 a 18- Alunos selecionados pela turma 801 apresentando o trabalho na IV FIMUCTI, Mendes-RJ.
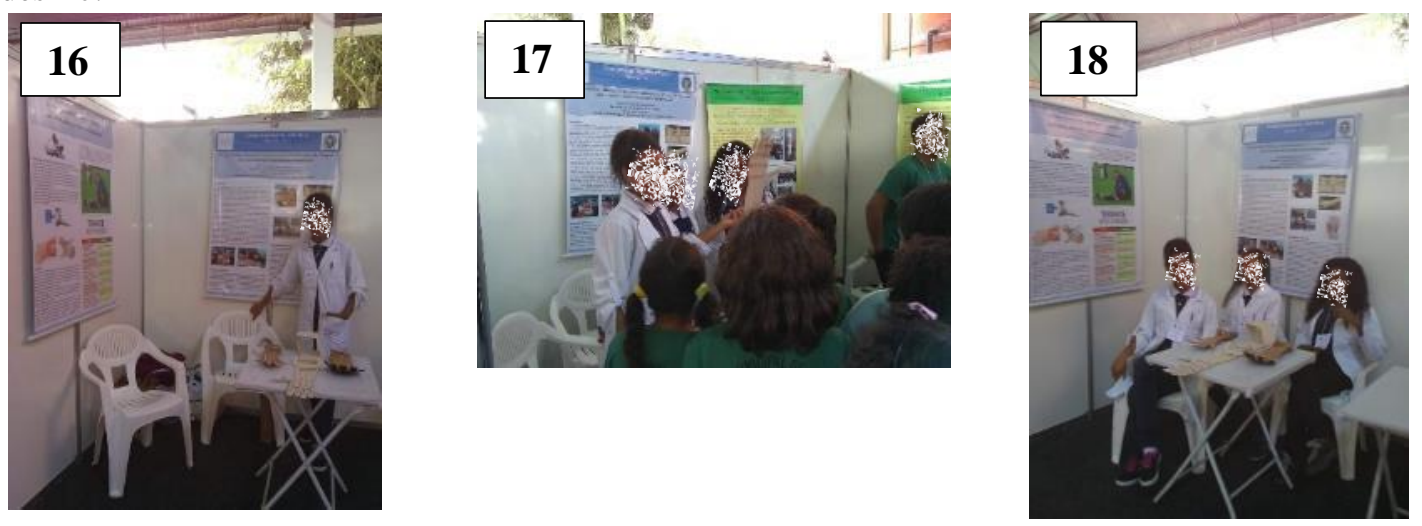

Fonte: acervo pessoal

\section{Resultados e Discussão}

Os resultados observados demonstram que os docentes conseguiram reduzir os muros artificiais que separam as disciplinas envolvidas, na execução da proposta interdisciplinar. Os alunos despertaram especial interesse no conteúdo através das práticas desen- volvidas, que proporcionaram a construção de uma ponte conectando o conteúdo acadêmico à realidade vivida por nossos educandos, além de apresentar relação direta com a qualidade de vida. A avaliação se deu através de manifestações livres compiladas por questionário desenvolvido para esta finalidade. Assim, por unanimidade, os alunos de- 
monstraram alcançar os objetivos estimados e o interesse em aprofundar suas descobertas nesta temática, revelando ainda a vontade de que outros assuntos em Ciências pudessem ser trabalhados de forma semelhante.

\section{Considerações Finais}

A era tecnológica mostra que, com o avanço do capitalismo e da modernização digital, o indivíduo que consegue ascender profissional e socialmente deve ser interpretativo, criativo, ágil de raciocínio e com capacidade de entender logicamente o funcionamento das coisas e do mundo à sua volta. Nessa era da informação rápida, a educação desempenha um papel impor- tante para inserir socialmente o aprendiz e, dessa forma, a escola deve revisar sua metodologia perante os novos obstáculos da atualidade, construindo o conhecimento de forma prazerosa e lúdica, fazendo uso de materiais que irão estimular a capacidade cognitiva do educando. No âmbito das ciências naturais essas atividades lúdicas fazem com que o aluno esclareça suas dúvidas, valorize o ambiente e reconheça que é também uma parte fundamental dele.

Lembremos que, para Paulo Freire, educar-se é conscientizar-se, e que conscientização significa desvelamento crítico das instâncias de dominação existentes na realidade e transformação dessa mesma realidade rumo a uma sociedade sem opressores nem oprimidos (FREIRE, 1970 e 1982). 


\section{Referências}

BONZANINI, T. K. Instrumentação para o Ensino: quais os saberes envolvidos. In: III Congresso Nacional de Formação de Professores e XIII Congresso Estadual Paulista sobre formação de Educadores: por uma revolução no campo da formação de professores. Anais do III Congresso Nacional de Formação de Professores e XIII Congresso Estadual Paulista sobre formação de Educadores: por uma revolução no campo da formação de professores, Águas de Lindóia, 2016.

BRASIL. Ministério de Educação e do Desporto. Secretaria da educação Fundamental. Parâmetros Curriculares Nacionais: terceiro e quarto ciclo do ensino fundamental: ciências naturais. Brasília, 1998

FAZENDA, I. C. A. Dicionário em Construção: Interdisciplinaridade. 3.ed.- São Paulo: Cortez. 2002.

FREIRE, Paulo. Pedagogia do Oprimido, Paz e Terra, Rio de Janeiro, 1970.

FREIRE, Paulo. Ação cultural para a liberdade, Paz e Terra, Rio de Janeiro, 1982.

RIO DE JANEIRO. Secretaria Municipal de Educação. Orientações Curriculares: Áreas Específicas: Ciências. Rio de Janeiro, 2010.

RONDINELLI, P. A Estrutura Curricular da Disciplina De Educação Física; Brasil Escola. Disponível em: <https://brasilescola.uol.com.br/educacao-fisica/a-estruturacurricular-disciplina-educacao-fisica.htm>. Acesso em 07 de fevereiro de 2020.

SANTOMÉ, J. T. Globalização e Interdisciplinaridade: o currículo integrado. Trad. Cláudia Schilling - Porto Alegre: Ed. Artes Médicas Sul ltda., 1998.

SOUZA, S. E. O uso de recursos didáticos no ensino escolar. In: I Encontro de pesquisa em educação, IV Jornada de prática de ensino, XIII Semana de Pedagogia da UEM: "Infância e práticas educativas". Anais do I Encontro de pesquisa em educação, IV Jornada de prática de ensino, XIII Semana de Pedagogia da UEM: "Infância e práticas educativas", Maringá, 2007.

TORTQUEMADA-GUERRA, R.A. [Org.]. Caderno Cb Virtual 5. João Pessoa: Ed. Universitária, 2010.

$O(s)$ autor(es) se responsabiliza $(m)$ pelo conteúdo e opiniões expressos no presente artigo, além disso declara(m) que a pesquisa é original.

Recebido em 12/03/2020

Aprovado em 22/06/2020 